Accepted version of Boud, D. and Brew, A. (2013). Reconceptualising academic work as professional practice: implications for academic development, International Journal for Academic Development, 18, 3 , 208-221. http://dx.doi.org/10.1080/1360144X.2012.671771

\title{
Reconceptualising academic work as professional practice: implications for academic development
}

\author{
David Boud and Angela Brew
}

\begin{abstract}
Despite increasing research and scholarship in the area of academic development in recent years, it remains an under-theorised field of endeavour. The paper pro- poses that academic developers take a view on what constitutes academic work and see it as a form of professional practice. It discusses the features of practice theory that illuminate professional practice and identities three foci for the application of these ideas within academic development: practice development, fostering learningconducive work and deliberately locating activity within practice. It also suggests that academic development be viewed as a practice and points to features within its own traditions on which to build.
\end{abstract}

Keywords: professional practice; practice theory; scholarship of practice; educational development

\section{Introduction}

The development of academics is based on the notion that institutions need to provide opportunities for their academic employees to develop across their range of roles. Any initial training (e.g. through undertaking a $\mathrm{PhD}$ ) is not sufficient for them to be able to meet the complex and increasing demands of the modern academy. Their development is an essentially pragmatic enterprise aimed at making an impact on academics and their work, prompted by perceptions that change is needed. This change has been stimulated variously by: varying needs and a greater diversity of students, external policy initiatives, accountability pressures and organisational desires to be seen to attend to the development of personnel. Typically, centres and units that go under a wide variety of titles and that deploy practitioners from many academic and other backgrounds provide a focal point for such development activities.

A growing sense that specialist knowledge and skills are required to carry out development work within higher education institutions has led to academic (educational/faculty) development becoming regarded as a distinct subset of the 
academic profession (see, e.g., Di Napoli, Fry, Frenay, Verhesschen, \& Verburgh, 2010; Lee \& McWilliam, 2008) with its own professional standards, recognition and training (in the UK, for example, through the SEDA Fellowships and training events). Attempts to specify a broad range of theoretical traditions on which it draws (e.g. Land, 2004; Manathunga, 2006; Taylor, 2011), to explore the complexity of evaluation strategies (Stefani, 2010) and to specify the knowledge base of academic developers (Peseta, 2011) are all examples of a growing scholarly approach to the recognition of the complexity of academic development work. In parallel with such discussions, some broad trends in academic development practice are discernable. For example, a concern that academic developers should be members of specific academic disciplines has now given way to more nuanced notions of the importance of context in framing academic work, and greater attention to institutional imperatives (Blackwell \& Blackmore, 2003) has led to more sophisticated dialogic notions of how such imperatives can be influenced by academic developers. Further, recognition of the ways in which academics combine and work simultaneously with teaching and research objectives (Colbeck, 1998) together with greater understanding of the ways in which workload is defined in universities have emphasised the need to take a more holistic and less individualistic approach to development.

These trends are all manifestations of the changing role of academic development vis-à-vis the work of academics. In this paper, we explore academic work as a professional practice and draw implications for academic development. We build on work from other professional development contexts and ideas from practice theory (Schatzki, 2001) to reconceptualise academic development through focusing on academic work as professional practice. Such a perspective not only draws attention to some positive features of development work that have been present throughout its history, but also questions some of the activities undertaken as insufficiently grounded in the social practices of academic work and those who undertake it, and as being implemented with insufficient consideration of the milieu required to support it. The paper explores ways in which development focuses on the need to utilise and extend opportunities for learning within the social and cultural practices of academics themselves. This perspective emphasises some aspects of current academic development practice, downplays others and points to new areas for exploration.

Traditionally, much development has focused on providing formal structured learning activities and/or participation in specified events. Developers, often prompted by their institutions, provide a range of opportunities principally to support teaching and learning, though also now on research supervision and management. Increasingly, institutions have moved away from developers deciding on which issues to focus. Blackwell and Blackmore (2003), for example, argue that institutional managers, drawing on strategic human resource 
development work and ideas of the learning organisation, should align academic with policy development. While some development focuses on working in situ with groups on particular issues, often the emphasis is on courses and workshops that take academics out of their normal context of work and treat different aspects of work - research, teaching, administration - as separate. Importantly, provision for academics is often specified and evaluated by people who themselves are not primarily practitioners of 'normal' academic work, such as academic managers and, indeed, academic developers themselves.

We suggest that a conscious focus on academic practice qua practice can fundamentally shift one's perspectives on professional learning. It moves from the consideration of learning as something that individuals do, to seeing learning as a social process occurring within the context of practice. Viewing learning as a constructed and emergent phenomenon arising in and from academic work positions academic development as a process of working with opportunities for learning created by work itself. Some aspects of this work foster, and others inhibit, learning, and an important task for the academic developer is to work with academics to engage with helpful and unhelpful facets of work in relation to their learning.

Thus, in this paper, we position and conceptualise academic development as focusing on academic work as a professional practice, and as being itself a professional practice. We do this in order to locate it not as a 'training and development' model but as a model of developing practice. Such an approach focuses on the practices of all kinds of academic work, and how these can be regarded as central to the academic profession, rather than, for example, on individuals' knowledge, skills and behaviours. In so doing, we provide a new rationale for the importance of some features of existing practice and a stimulus for the emergence of new development practices.

We propose that the development of academics needs to focus on utilising opportunities in everyday work and finding ways of addressing the limitations of learning in the normal context of academic practice. More emphasis, we suggest, needs to be given to involving practitioners in environments that afford them opportunities to extend their own practice through participation in the practices of others. In this, we build on and partly reprise the arguments of Boud (1999) in which he proposed fostering a greater focus on peer learning in context. Here, we take this further and suggest that new perspectives can generate a new focus linked to the professional practice of academics.

\section{Challenges of academic development}

Like most forms of education and training, academic development is continually at risk from what might be termed 'provider-capture', that is, it becomes driven by 
the needs of providers and those who sponsor them, rather than the needs of beneficiaries. In the wider continuing professional education arena this occurs, for example, through professional bodies identifying needed development for their members, set- ting up programmes and events which start from a perceived need, but which then become routinised and institutionalised and eventually take on structures and imperatives of their own. Business models become dependent on throughput of participants and programmes become accountable not for the outcomes in terms of changed practice, but for the number and quality of courses and interventions provided. This produces an inevitable shift from prioritising the needs of professionals to prioritising the needs that can be met through a particular provision or provider. In the case of academic development, this emphasis can be manifest in a focus on centralised events, workshops for groups who do not work together, reporting procedures that count participation rather than effects and activities driven by policy initiatives rather than identified needs.

In common with all provision-driven continuing professional education then, academic development has a tendency to adopt a deficit model. It assumes that the professionals subject to provision lack something that needs to be remedied; their awareness needs to be raised and new skills and knowledge made available. The assumption underpinning this is that without intervention, the deficit will not be addressed and academics not developed.

Such a characterisation, many developers would protest, does not represent what they do. They would argue that they are assiduous in consulting those affected by what they do, they collect good data on the performance of programmes and they adjust what they do in the light of feedback. In implementing Foundations in Learning and Teaching programmes and Graduate Certificates in Teaching and Learning in Higher Education, they include opportunities for academics to address issues in their own teaching, to research their students' learning and to engage in critical reflection on their practice. Developers undoubtedly cultivate high levels of skill in communicating and articulating their activities for such a demanding group. Nevertheless, they are positioned within their institutions to do what is required of them by their organisation, not by those they claim to serve. Their ultimate client is the organisation, not the practitioner, and this generates dilemmas in their practice.

The positioning of development initiatives anywhere other than within the groups and environments with which academics identify, means that they are always at the risk of being dislocated. Connecting the sites and cultures of development to the sites and cultures of practice is an ongoing challenge. This applies no matter which aspect of the academic role is considered. Developers often work with departmental teaching and learning committees and with teams designing new courses, and in that sense, they are working at sites of practice, but without this 
being carried through to classroom implementation, it could be argued that it is still separate from the everyday sites of academic practice. Activity placed away from grounded sites of practice (classrooms, laboratories, etc.) may not take sufficient account of academic workplace cultures. Discussion of changing teaching practices, for example, inevitably leads to the discussion of challenges in the academic work- place which inhibit effective development, such as workload issues, student contact hours, the need to meet research performance goals and so on. Even emphasising one aspect of academic work (e.g. teaching) over another (research) reinforces a deficit model. It assumes that the other, by implication, is acceptable, or dealt with elsewhere (e.g. in research offices). Disconnection between the locations of teaching, research and development attends to the wrong objects. It fails to address the materiality of practice.

\section{A view from practice theory}

There has been a profound shift in contemporary social theory away from considering attributes of people and things as if they were separate from the ways they operate together in the world, to conceptualising phenomena as connected, located and grounded in the practice of particular events and activities. This has become known as the practice turn. While the practice turn has played out differently in different disciplines, it has influenced all the social sciences in various aspects (Schatzki, 2001). In this view, we no longer look at knowledge and learning, for example, as if they were features of individuals, but as they are played out in specific practice interactions with material objects, addressing everyday issues as they emerge. The frame for seeing the world focuses on the practices enacted and the doings and sayings that constitute them. Such a practice view helps us understand, for example, why practices persist even when the individuals involved change.

There are many approaches to practice theory with different emphases and orientations on which to draw. Schatzki's approach has particularly influenced the approach taken in this paper. He views practice as:

a temporally and spatially dispersed set of doings and sayings that are linked in certain ways. Through: understandings of what to do and say, explicit rules, principles, precepts and instructions, and teleoaffective structures of ends, projects, tasks, purposes and beliefs, emotions and moods. (Schatzki, 1996, pp. 89-90)

From ideas in the organisational literature, Gherardi (2008) identified several streams of research that she terms 'practice-based studies': cultural and aesthetic approaches, situated learning theory, activity theory, actor network theory and work- place studies. These streams of research have in common a focus on practice as located, mediated and relational. 
Most of these streams move away from the conventional educators' focus on competences of the individual and the knowledge and skills that they acquire to focus on practices in which activity, rather than the person or their attributes, is central. They insist that relational features be considered together, so the practice entails relationships between those involved and how they respond to and act on the material aspects of the situation. Practice integrates through linking thinking with doing and people with contexts. Change to any one of these elements changes practice. Six partly overlapping features of practice are apparent in various practice theories and these can be usefully considered: embodiment, material mediation, relationality, situatedness, emergence and co-construction.

\section{Embodiment}

A practice view necessarily implies embodiment, as it is the whole person who engages in practice, not just their intellect and skills. For Kemmis (2009, p. 23), practice is 'always embodied (and situated)' encapsulating: 'what particular people do, in a particular place and time, and it contributes to the formulation of their identities as people of a particular kind, and their agency and sense of agency'. Desires, emotions and values are ever present and cannot be separated out.

\section{Material mediation}

Practice is undertaken in conjunction with material arrangements. These may include objects such as raw materials, resources, artefacts and tools, physical connections, communication tools, organisms and material circumstances (Kemmis, 2009). These materials can both limit and enable particular practices. They are intrinsic to many practices.

\section{Relationality}

People, artefacts, social groups and networks develop characteristics in relation to other subjects, social groups or networks such that they are formed and structured socially (Kemmis, 2009). Practice occurs in relation to others who practice, and in relation to the unique features a particular practitioner brings to a situation. Practice is thus embedded in sets of dynamic social interactions, connections, arrangements and relationships. Communities of practice (Lave \& Wenger, 1993), for example, provide a relational network of interactions to sustain and foster particular practices.

\section{Situatedness}

There are many ways in which practice is located. It is situated in particular settings, in time, in language and in the dynamics of interactions (Gherardi, 2008, 
p. 521). For Kemmis $(2009$, p. 22), practice "has aspects that are "extra-individual" in the sense that the actions and interactions that make up the practice are always shaped by mediating conditions that structure how it unfolds'. These may include cultures, discourses, social and political structures, and material conditions in which a practice is situated.

\section{Emergence}

Practices evolve over time and over contexts: new challenges require new ways of practising. Practices emerge in unanticipated and unpredictable ways: 'from contingently formed patterns of understandings and interactions when actors enact the practical and situated work activities with others, often using material resources in their environment' (Johnsson \& Boud, 2010, p. 360).

\section{Co-construction}

Practices are co-constructed with others. That is, the meaning given to practice is the meaning that those involved give to it. These others may be peers but also include clients, sponsors, recipients and other workers. Many practices only become legitimate or worthwhile when they are co-constructed with beneficiaries. Health and education are examples of areas in which this occurs.

To summarise: practice is necessarily contextualised; it cannot be discussed independently of the settings in which it occurs; it is embodied in those undertaking the practice. Discussion of it in isolation from those who practice and where it occurs is to misunderstand practice. It is necessarily constructed with others and it always involves working with those whose volition is a key consideration. A practice orientation goes beyond acknowledging the importance of activities or the agency of people who perform them. It focuses attention on the nature of the associations connecting people and artefacts in dynamic, interactive and provisional ways that give rise to understandings of a relational theory of action. Exploring the various elements of practice set out above holds promise for some satisfying new ways to understand and theorise professional learning.

It is important to be clear about what this emphasis on practice and practice theory is not. It is not about being more practical or more pragmatic or less theoretical. Quite the opposite: it involves theorising practice and using practice as adopted in practice theory as the lens through which to judge academic development. Therefore it is neither a part of a discredited theory/practice polarity, nor an attempt to deny the importance of values and principles.

Rather than be distracted by particular activities, it is important to focus first on the general implications and emphases that a practice-centred approach generates. A new conceptualisation does not necessarily in itself lead directly to changed 
activities on the part of the developer. It points to a different way of viewing and talking about their work which then gets played out in the practices of developers as they are confronted with their own contexts of operation. In some cases, this shift will be minor, but in others substantial.

\section{What does adopting a practice frame imply for academic development?}

What then does academic development look like through the lens of practice theory? A practice frame moves academic development from a focus on individuals and learning needs to academic practice and practice needs; from what academics need to know to what they do to enact their work. It also moves it from decontextualised locations such as seminar rooms in centralised units, and the need to transfer learning from such places to settings of application (e.g. classrooms and laboratories), to building from practice, that is, the embodied, contextualised activities academics engage in with others including their peers, their managers and students. It does not deny knowledge and skills, but also it does not privilege them. It focuses on what is done and what needs to be done, not on the individuals enacting the doing.

Professional practice involves interactions with a variety of others in a range of contexts. Tangible issues commonly drive such interactions. Much of the learning involved arises when the exigencies of work are questioned. Some of these challenges fall within the conventional boundaries of that work, such as when members of research teams have different interpretations of data, but others arise outside these and need to be addressed from beyond the knowledge and skills of the practitioner. One example is when teachers used to taking individual responsibility for a module, are grouped to take responsibility for a number of modules. Other learning takes place only when the conduct of work requires it. The most powerful influence is not the provision of learning opportunities but changing work demands to drive learning.

What holds together all the sites and purposes and relationships is that they cohere with the notion of practice. It is what professionals do which is the centre- piece of their learning challenges, whether they are academics or academic development personnel. They undertake practice, they extend their practice and they take up new practices. Learning is driven by, for example, encountering new groups of students with different needs and expectations, or by working with a new issue not previously identified. Success in learning is judged by how successfully the practice with the new group or new issue is undertaken, not by how much is learned by the individuals involved that could be tested by formal assessment processes. Practice drives learning, not only to solve immediate problems, but also to address wider concerns. The most compelling learning occurs when it is seen by practitioners as needed in order to do their own work. That is, when learning is an 
imperative, not an option.

We suggest that a practice perspective would thus place greater emphasis on the development of academics:

(1) as practice development, emphasising the practices in which academics engage and how these practices might be extended;

(2) as fostering learning-conducive work, where 'normal' academic work practices are reconfigured to ensure that they foster practice development; and

(3) as consciously located activity within practice, in which academic developers take explicit account of the nature and variety of the contexts of practitioners.

\section{Practice development}

Practice development starts with a concern for the nature of a specific practice: is it doing what it purports to do? Is it the most appropriate thing to do in the circumstances? Is there evidence that alternative ways of practising might be needed? What is needed to address constraints in changing practice? It builds from what is to what needs to be and seeks to find support for sustaining this in the practices and culture that surround the focus of development.

In considering practice development, it is increasingly necessary to consider that academic work is becoming more collective rather than individual in nature, involving co-producing practice with others, particularly students and coresearchers.

In referring to academics, academic developers often talk of and work with particular aspects of their role as if that were the whole of the person's concerns, with- out taking into account the fact that this is just one aspect. Working with individual academics to meet institutional imperatives, for example, curriculum reform, comes up against various stumbling blocks where academics complain that they are over- worked, that there is too much to take on and that their colleagues are not supportive of what they are trying to do. Practice development means working with how the group juggles various aspects of their role and their attitudes and beliefs in relation to that. It is about how the group interacts in pursuing its practice, how and whether interpersonal relationships take account of the being of its members, how power and authority are negotiated, whose ideas are listened to and taken up and whose are denied. 


\section{Learning-conducive work}

Some work practices and conditions are more conducive to learning than others. Considerable potential for development occurs through organising and conceptualising work in ways that support learning. If substantial learning is needed to sustain the demands of academic work, then work needs to be arranged in such a way as to be conducive to learning, rather than antagonistic to it.

Hutchings and Shulman (1999) highlighted this in establishing the idea of the scholarship of teaching and learning. They suggested that academics do not develop their practice in teaching in the normal process of doing it. Turning the practice of teaching into a scholarly endeavour that goes beyond the particular classroom and engages teachers in scholarly discussions about teaching with colleagues turns teaching into work facilitative of learning.

What might learning-conducive work look like? An analysis was undertaken in a variety of Norwegian organisations (Skule \& Reichborn, 2002). While these organisations were not educational ones, the outcomes are suggestive of what we might wish to consider. The authors make the point that:

All things being equal, neither gender, education, the competitive situation, size of company nor type of industry are particularly significant when it comes to the opportunity to learn through work. It is the various properties of work - what we call learning conditions - that are most important in explaining the differences in the opportunity to learn through work. (Skule \& Reichborn, 2002, p. 10)

These researchers identify seven learning conditions for work:

(1) high degree of exposure to demands from customers, management, colleagues and owners;

(2) high degree of exposure to changes in technology, organisation and work methods;

(3) managerial responsibility;

(4) a lot of external professional contact;

(5) good opportunity for feedback from work;

(6) support and encouragement for learning from management; and

(7) high probability that skills will be rewarded through interesting tasks, better career possibilities or better pay. 
A number of these conditions depend on the organisation and policies of the institution. For example, the way managerial responsibilities are determined, how and whether there is a formal system for feedback and opportunities for promotion and advancement. However, there is a role for academic developers in working with academics and academic managers to develop understanding of the factors that foster/inhibit the integration of learning and work. Changing work is probably the most powerful driver for development. Again, taking a prompt from the world of work- place learning, we might consider the factors identified in Swedish workplaces by Ellström. These are:

- the learning potential of the task in terms of task complexity, variety and control;

- opportunities for feedback, evaluation and reflection on the outcomes of work actions;

- the type and degree of formalisation of work processes;

- organisational arrangements for employee participation in handling problems and developing work processes; and

- learning resources in terms of, e.g., time for analysis, interaction and reflection (Ellström, 2001).

Similarly, in reflecting on the importance of the everyday circumstances of work itself in creating possibilities for change as well as strongly inhibiting it, Fuller and Unwin (2004) identified the features of what they termed expansive and restrictive participation in work based on the extent to which work is structured to enable or circumscribe opportunities to develop. Many of their expansive features are common in the academic workplace and the restrictive features less so. This points to the issue that it is not simply the intrinsic potential of the workplace that affords development, but how it is perceived and what sustains restrictive practices. To understand this, we need to look to the myths and assumptions held by academic practitioners that make them think that their work is restrictive. We believe that there is far greater potential to change work in academic workplaces than in most other professional environments.

For academics, practice development involves confronting the competing and sometimes contradictory demands on them, and marrying these disparate requirements. It may mean developers start with what is most problematic for any given group and working with that, rather than with some issue preconceived by academic managers or developers: the introduction of a new virtual learning environment (VLE) that teachers are required to utilise, for example. It demands that developers examine their own practices and consider how they can be more effectively subordinated to the practices they are influencing. So, for example, developers come to understand how the VLE is going to be used by a group of academics in specific contexts and work alongside them to ensure that the changed 
practices have the desired effects on students.

\section{Consciously locating activity within practice}

Intrinsic to a practice focus is the notion of locatedness. Practice always takes place in and is positioned within particular contexts. Location, however, is not just about proximity. It can have a number of dimensions, each of which may need to be considered on any occasion of development. These include the spatial, the temporal, the personal, the social and the professional.

Spatial location (where?)

This involves close alignment of activities with sites of practice. Some of this has already become common academic development practice, such as working in academic departments alongside academics, in course teams working on curriculum development, attending lectures and classes and providing feedback. It might also mean facilitating action learning sets to solve problems in the workplace, or working with teams of academics researching their teaching and learning.

Temporal location (when?)

Alignment of development opportunities during normal practice: the common prac- tice of peer observation of a lecture and a subsequent conversation to provide direct feedback is an example of this. This contrasts with development at some time removed when the practice is not occurring. The timeliness of development interventions is crucial: a worthwhile conversation in one week of the semester may be worthless in another.

Personal location (with which practices?)

Working with individuals' integration of practices and identities. This might mean working with academics across their responsibilities with a view to addressing tensions: working, for example, with a group of academics to solve problems with workload and the balance of different activities, e.g., teaching and research.

Social location (with which others?)

Working with groups that practice. This might mean working in research teams or course teams, participating in research and teaching committees.

Professional location (within which professional/disciplinary context?)

Working on developments in professions and disciplines that form significant identities for action. So, for example, the developer may work with academics in 
translating professional practice requirements into student-friendly learning outcomes.

Of course, in any given instance, particular features of locatedness are more salient than others. The challenge for developers is to consider carefully whether any given act of development is sufficiently well located to impact practice.

\section{Building on productive themes in academic development}

Is this practice focus new? Clearly, academic development has never been centralised, programmatic and unrelated to immediate practice. There is a complex and multi-faceted set of practices in this area, each with its own tradition. Practice theory has already been used in discussing a professional development programme for new academics (Räsänen, 2009) and to provide a critique of proposed compulsory teacher training for academics (Trowler \& Bamber, 2005). We wish to go beyond these specific foci and propose practice as a new overarching frame that will accommodate some features from current academic development practice memory, but that will challenge others. More important is the possibility of generating new kinds of practice stimulated by this perspective.

There are a number of well-established themes in existing and historical academic development work from which a practice-based view can build, though each will need to be extended further. These include emphases on the notions of the project, the use of consultancy and reflective practice.

\section{Project theme}

Early 1960s initiatives in academic development in Australia were driven by high student failure rates; they were research-based and aimed to change practice (Lee, Manathunga, \& Kandlbinder, 2008). They took the form of projects that investigated the problem and worked to implement solutions. While these initiatives often stopped short of directly engaging practice, they worked with groups of practitioners and sought to address substantial problems. This projectbased emphasis continues today and has become more sophisticated in its approach, extending to monitoring impacts on practice and working iteratively to solve problems through action research cycles of collecting data, instituting change and examining effects. In Australia, for example, many Australian Learning and Teaching Council grants have been facilitative of this approach. In a practice perspective, the key emphasis is on constituting the team. Membership from the start is often suited to putting out- comes into practice.

\section{Consultancy theme}

Another well-established approach is the use of consultancy to assist individuals 
and teams to address problems that they have identified (Boud \& McDonald, 1981). Drawing from management consultancy traditions, consultancy in academic development utilised internal process consultancy strategies to work with academics over time to enable them to reach their own solutions. The consultancy theme involves building relationships and taking account of the exigencies of situations in which academics find themselves. A variation on the consultancy theme is the team theme: rather than basing itself on individual issues, it works with teams of academics with collective responsibility for an initiative. Problem-definition and implementation is a collective act, aided by an academic development consultant. The emphasis in a practice perspective is on working with intact groups in situ that also include those who manage the programmes or practices that are the objects of attention.

\section{Reflective theme}

The reflective theme commonly manifests itself as a way to cope with the limitations of the centralised, accredited course approach. In formal academic development programmes, assignments are used that, rather than addressing a developer-initiated issue, use experiences of staff in day-to-day teaching as the focus of study. While this has often been an individualistic activity in the tradition of Schön's (1983) reflective practitioner, more group-based approaches may be drawn on (e.g. Cressey \& Boud, 2006). While the reflective theme necessarily builds on the practice experience of individuals, the wider practice view moves beyond the person who practices to a more collective approach in which the appropriate set of practitioners reflect on the issues that mutually confront them.

One trend in the development of reflective practice has been the use of research on practice to effect change. In particular, the scholarship of teaching and learning is now widely used as a mechanism for academics to understand more about how students learn on their courses and as resources for reflection on teaching. Brew (2010) suggested that this practice needs to be extended to academic work more generally and has proposed a scholarship of academic practice.

An important challenge to academic development in responding to the practice turn is the competing and conflicting demands in developers' own practice. Developers are squeezed between the exigencies of the practices of the academics with whom they work, and the increasingly influential practices of their own managers and institutional policy-makers. As academic development came of age, and probably lost its innocence, it ceased to be driven by developers who acted as the con- science of the institution and as surrogates of relatively voiceless students, to become agents of corporate policy and strategic plans (Lee et al., 2008). It needs to recognise that if it wants to be recognised as a legitimate academic activity in its own right, it must find ways of managing the tensions between what 
may be characterised as the extremes of 'selling out to management' and acting as servants to practitioners. If it can conceptualise a sophisticated role and set of practices grounded in a value position and a sense of its own professional practice, it can thrive in the demanding cultures of the academy.

\section{Conclusion}

This paper has explored the implications of a practice perspective for academic development. It has suggested that academic development for continuing professional learning needs to be increasingly located in the practice of professionals. It must move ever closer to everyday practice and the materiality of academic work, influencing work settings to support continuing learning. It must recognise that all practitioners have a particular scope of practice and that development involves extending that scope. A practice perspective moves development away from deficit assumptions about academics' skills and knowledge and considers all aspects of academic work. There is a focus on the development of practice, but not on the development of the individual.

Finally, recognising that academic development practice may be different to the practices of departmental academics, academic developers also need to pay attention to their own practice. This is the focus of much of the scholarly work on academic development, but it needs to be grounded in theories of practice. As academic developers work with and encourage faculty academics to learn through practice, so the tensions between institutional expectations and professional practice of academic development provide opportunities for their own professional learning.

\section{Notes on contributors}

David Boud is Professor of Adult Education in the Faculty of Arts and Social Sciences, University of Technology, Sydney. He is a Senior Fellow (National Teaching Fellow) of the Australian Learning and Teaching Council, a Fellow of the Society for Research into Higher Education and a life member of the Higher Education Research and Development Society of Australasia (HERDSA). He was president of HERDSA from 1988-91. His current research is focused on learning in workplaces, assessment for learning and research education. Recent books (with various others) include: Productive Reflection at Work: Learning for Changing Organisations, Rethinking Assessment in Higher Education: Learning for the Longer Term and Changing Practices in Doctoral Education (all Routledge).

Angela Brew is a professorial fellow in the Learning and Teaching Centre, Macquarie University, and a national teaching fellow of the Australian Learning and Teaching Council. An experienced academic developer, she is a fellow of the Society for Research 
into Higher Education, a life member of the Higher Education Research and

Development Society of Australasia and a senior fellowship holder of the Staff and Educational Development Association (SEDA). She was president of HERDSA from 1999-2003, and co-editor of the International Journal for Academic Development from 2000-2008. Her research is focused on the nature of research and its relation to teaching, learning and scholarship, models of research-led teaching and undergraduate research. Her books include: The Nature of Research: Inquiry in Academic Contexts (RoutledgeFalmer); Research and Teaching: Beyond the Divide (Palgrave Macmillan); Transforming a University: The Scholarship of Teaching and Learning in Practice (University of Sydney Press, with Sachs); and Academic Research and Researchers (McGraw Hill, with Lucas).

\section{References}

Blackwell, R., \& Blackmore, P. (2003). Towards strategic staff development in higher education. Maidenhead: Society for Research into Higher Education and the Open University Press.

Boud, D. (1999). Situating academic development in professional work: Using peer learning. International Journal for Academic Development, 4(1), 3-10.

Boud, D., \& McDonald, R. (1981). Educational development through consultancy. SRHE Monograph. London: Society for Research into Higher Education.

Brew, A. (2010). Transforming academic practice through scholarship. International Journal for Academic Development, 15(2), 105-116.

Colbeck, C. (1998). Merging in a seamless blend: How faculty integrate teaching and research. Journal of Higher Education, 69(6), 647-671.

Cressey, P., \& Boud, D. (2006). The emergence of productive reflection. In D. Boud, P. Cressey, \& P. Docherty (Eds.), Productive reflection at work: Learning for changing organisations (pp. 11-26). London: Routledge.

Di Napoli, R., Fry, H., Frenay, M., Verhesschen, P., \& Verburgh, A. (2010). Academic development and educational developers: Perspectives from different European higher education contexts. International Journal for Academic Development, 15(1), 7-18.

Ellström, P.-E. (2001). Integrating learning and work: Problems and prospects. Human Resource Development Quarterly, 12(4), 421-435.

Fuller, A., \& Unwin, L. (2004). Expansive learning environments: Integrating organizational and personal development. In H. Rainbird, A. Fuller, \& A. Munro (Eds.), Workplace learning in context (pp. 126-144). London: Routledge.

Gherardi, S. (2008). Situated knowledge and situated action: What do practice-based studies promise? In D. Barry \& H. Hansen (Eds.), The Sage handbook of new approaches in management and organization (pp. 516-525). London: Sage. 
Hutchings, P., \& Shulman, L. (1999). The scholarship of teaching: New elaborations, new developments. Change, 31(5), 10-15.

Johnsson, M., \& Boud, D. (2010). Towards an emergent view of learning work. International Journal of Lifelong Education, 29(3), 355-368.

Kemmis, S. (2009). Understanding professional practice: A synoptic framework. In B. Green (Ed.), Understanding and researching professional practice (pp. 19-38). Rotterdam: Sense.

Land, R. (2004). Educational development: Discourse, identity and practice. Maidenhead: Society for Research into Higher Education and the Open University Press.

Lave, J., \& Wenger, E. (1993). Situated learning: Legitimate peripheral participation. Cambridge: Cambridge University Press.

Lee, A., Manathunga, C., \& Kandlbinder, P. (Eds.). (2008). Making a place: An oral history of academic development in Australia. Sydney: HERDSA.

Lee, A., \& McWilliam, E. (2008). What game are we in: Living with academic development. International Journal for Academic Development, 13(1), 67-77.

Manathunga, C. (2006). Doing educational development ambivalently: Applying postcolonial metaphors to educational development? International Journal for Academic Development, 11(1), 19-29.

Peseta, T. (2011). Professing in the field of academic development: Is content a dirty word? International Journal for Academic Development, 16(1), 83-86.

Räsänen, K. (2009). Understanding academic work as (practical) activity and preparing (business school) academics for praxis. International Journal for Academic Development, 14(3), 185-195.

Schatzki, T. (1996). Social practices: A Wittgensteinian approach to human activity and the social. Cambridge: Cambridge University Press.

Schatzki, T. (2001). Practice theory. In T. Schatzki, K. Knorr-Cetina, \& E. von Savigny (Eds.), The practice turn in contemporary theory (pp. 1-14). New York, NY: Routledge.

Schön, D. (1983). The reflective practitioner: How professionals think in action. New York, NY: Basic Books.

Skule, S., \& Reichborn, A. (2002). Learning-conducive work: A survey of learning conditions in Norwegian workplaces. Luxembourg: CEDEFOP.

Stefani, L. (Ed.). (2010). Evaluating the effectiveness of academic development. London: 
Routledge.

Taylor, K.L. (2011). Shining the light on inquiry: Diverse goals, conceptual lenses and methods in academic development scholarship. International Journal for Academic Development, 16(2), 93-95.

Trowler, P., \& Bamber, R. (2005). Compulsory higher education teacher training: Joined up policies, institutional architectures and enhancement cultures. International Journal for Academic Development, 10(2), 79-93. 